\title{
Effects of Gamma Irradiation on Seedlessness and Fruit Quality of Ortanique Tangor
}

\author{
Berken Çimen ${ }^{1, a^{*}}$, Turgut Yeşiloğlu ${ }^{1, b}$, Yıldız Aka Kaçar ${ }^{1, c}$ \\ ${ }^{1}$ Department of Horticulture, Faculty of Agriculture, Cukurova University, 01330 Adana, Turkey
}

*Corresponding author

A R T I C L E I N F O
Research Article

Received : 10/10/2019
Accepted : 12/12/2019

Accepted : 12/12/2019

A B S T R A C T

The existence of a large amount of seeds in citrus fruits results as a major impediment to customer acceptability, even if the fruits have high organoleptic properties. Irradiation, which mainly reduces seed number of varieties, is a faster way than hybridization. The use of irradiation in citrus breeding programs is now quite widespread with most programs in the major citrus producing countries actively developing new selections. The present study reports the primarily results of gamma irradiation on seed number and fruit quality of Ortanique tangor mutant population. The shoots of scion were irradiated with gamma rays from ${ }^{60} \mathrm{Co}$ at the dose of $50 \mathrm{~Gy}$ (gray) in April of 2014. All the treated buds were then immediately budded onto rootstocks and the survival rate was recorded as $60.34 \%$. In order to stabilize the mutation, $\mathrm{mV}_{3}$ plants were developed by re-budding and plants

Keywords:

Citrus at $\mathrm{mV}_{3}$ generation were transplanted in the orchard in 2017. Within the following year, $68 \mathrm{mV}_{3}$

Mutation breeding

Mandarin plants out of 852 grown in the field bore sufficient amount of fruit and were screened in terms of 19 fruit quality characters such as seed number per fruit, fruit diameter and ripening index. Fruit Selection Fruit quality diameters of $\mathrm{mV}_{3}$ population varied from $56.72 \mathrm{~mm}$ to $84.79 \mathrm{~mm}$, and fruit weight ranged between $90.00 \mathrm{~g}$ and $287.60 \mathrm{~g}$. The number of seeds per fruit ranged between 0.6 and 13.1 whereas seed number of non-irradiated Ortanique tangor was recorded as 10.7 in the same fruit crop year. In general, fruit characteristics such as fruit weight, fruit height and fruit diameter which describe fruit size of a big part of the population, were similar to Ortanique tangor. According to primarily results, 18 plants have been described as low seeded $(\leq 4)$. In addition, a cluster analysis was performed by using Euclidean similarity coefficient and similarity index ranged between $29.29 \%$ and $93.10 \%$ regarding variables related to fruit. The stability of mutations detected is being evaluated and new commercial field trials will be established with the selected materials.

\footnotetext{
a bcimen@cu.edu.tr

\section{Introduction}

Citrus fruits are the most commonly produced fruit group in the world due to their high nutrition capacity and their usage in industry. Turkey has exceptionally suitable environmental conditions and citrus-producing prospective, with 4.769 .726 tons of citrus fruit produced in 2017 (FAO, 2019). Turkey's fresh mandarin production has expanded considerably over the years, approaching approximately 1.5 million tons in 2017 . Currently, $65 \%$ of Turkey's fresh fruit exportation is citrus fruits and, there has been a large increase in the exportation of citrus fruits in recent years, especially for mandarins. Mandarins are called 'easy-peelers' because of their sweet flavour and aroma, loose skins, relatively small fruit size among the edible citrus and are easy to peel and separate into segments (Demirkeser et al., 2009). Mandarins remain the most consumed and demanded citrus species due to serious advantages, such as smaller fruit, thinner skins, easy peeling and export possibilities. Nevertheless, there is still a great deal of work in citrus breeders to further enhance the quality of mandarin fruits and to offer customers new, tasty, healthy and easy to eat seedless fruits.

Citrus varieties have been cultivated in more than 100 countries among the world, and nearly all of the producer countries are working intensively on improving fruit quality in order to increase their share in export markets. Recently, seedlessness is one of the most desired quality parameters demanded by both producers and consumers in citrus fruits. Because of some aroma compounds and 
bitterness, seedy varieties are unwanted also by the juice industry (Ollitrault et al., 2008).

Breeding of the fruit crops started with the selection of superior genotypes that appear spontaneously in nature since the date of fruit consumption (Çimen, 2018). Examining the source of the genetic variability of citrus, it had been reported that all species and varieties were originated from citron, mandarin, pummelo and $C$. micrantha Wester (Ollitrault et al., 2012). Commercially cultivated recent varieties are developed from these four species by spontaneous and artificial mutations and crosses. However, Citrus breeding has been confronted with difficulties such as high heterozygosity, polygenic traits and a long juvenile period, regardless of breeding techniques used. Because conventional hybridization method takes long time and is costly, researchers focused on mutation breeding. Generally, the main objective in mutation breeding is to improve the existing variety in terms of seedlessness, harvest time, fruit rind and juice colour, or to transfer the targeted trait (Çimen, 2018).

Spontaneous mutation selection is the oldest technique of citrus breeding, and this process has resulted in most of the varieties grown globally. However, these mutations appear at a low frequency in nature. The occurrence of natural bud sports in citrus gained the attention of fruit breeders through induced mutation. Red flesh coloured Star Ruby variety developed by Hodgson grapefruit is known to be the first example of mutation breeding in citrus. A serious number of commercially important varieties, such as Washington navel orange, Marsh grapefruit, Shamouti Orange, and Salustiana sweet orange, have been developed as bud mutation. Today, several seedless varieties such as Tango, Daisy SL, Fairchild SL, and Kinnow SL were improved from, W. Murcott, Daisy, Fairchild and Kinnow varieties by mutation breeding and they are commercially cultivated (Hensz, 1971; Williams and Roose, 2008a, 2008b). Besides, Shahid et al. (2011) reported that the seed number of Kinnow was reduced from 25 to 5 seeds per fruit by irradiation of 20 gray of ${ }^{60} \mathrm{Co}$ gamma irradiation. Similarly, Handaji et al. (2016) studied effects of gamma irradiation on fruit quality of Marisol Clementine mandarin and reported that six of the mutant individuals were seedless and had higher fruit diameter in comparison to non-irradiated Marisol Clementine variety.

Studies on citrus breeding began in our country in the 1960s, however the required standard has still not been met up to date. In addition, the majority of our citrus production lands consist of foreign originated varieties. In order to change this situation, it is necessary to start new breeding studies and to develop populations containing sufficient number of individuals in order to select genotypes those have the targeted traits.

In terms of improving new varieties those are suitable for our country's ecological conditions, new mandarin populations should be developed for increasing share in the export markets, expanding harvest time, mid-late and late ripening, high fruit yield and quality and especially for seedlessness. In the present study, seed number and fruit quality traits of Ortanique tangor mutant population derived by gamma irradiation were investigated and the primarily results of the mutant population regarding pomological traits were presented.

\section{Materials and Methods}

\section{Plant Material}

This study was carried out at the Citrus AdaptationMutation Orchards located at the lands of Horticulture Department of Cukurova University (Adana, Turkey). Mutant plant population at $\mathrm{mV}_{3}$ stage derived by irradiation of Ortanique tangor were used as plant materials. Ortanique tangor is discovered in Jamaica which is a very vigorous variety. It is a most reliable and productive bearer, the fruit maturing late in the season about the same time as the Valencia orange. The fruits of Ortanique tangor are of medium size, and the shape, peel texture and thickness, as well as external colour and internal quality are affected greatly by the area in which the variety is produced. The juice is of outstanding colour, especially from origins other than those with tropical climate, while the flavour is extremely sweet but well balanced with acidity and has a strong, rich aroma. Seediness is variable and is obviously affected by pollination (Saunt, 2000).

\section{Irradiation Treatment and Development of $m V_{3}$ Mutant Population}

Mutagenesis was induced by subjecting dormant buds of Ortanique (Citrus reticulata Blanco x Citrus sinensis L. Osbeck) to gamma irradiation using ${ }^{60} \mathrm{Co}$ at the dose of 50 Gy (gray). A total of 58 Ortanique budwoods were used for irradiation. After irradiation treatment, budwoods were immediately grafted on to sour orange (Citrus aurantium L.). The number of surviving budwoods was measured three months after grafting and the survival rate of budwood was recorded as $60.34 \%$ at $\mathrm{mV}_{1}$ stage. In order to stabilize the mutation, buds in the middle of the first shoots of $\mathrm{mV}_{1}$ plants were extracted, grafted on to sour orange and $174 \mathrm{mV}_{2}$ plants were obtained. In the following year, this process was repeated again at $\mathrm{mV}_{2}$ stage and 852 $\mathrm{mV}_{3}$ individuals were recovered. Mutant seedlings were then planted in 2017 with $4 \times 1.5 \mathrm{~m}$ spacing in order to investigate pomological characteristics.

\section{Pomological Analysis}

In the observations made in December 2017, it was determined that 68 out of 852 mutant Ortanique plants bore more than 10 fruits. In March 2018, fruit samples were harvested from 68 mutant individuals and pomological analyses were performed in these fruit samples. Fruits samples harvested from non-irradiated Ortanique tangor located at the experimental orchard were evaluated as control in the study. Pomological analyses of fruits harvested in the experiment were performed according to Özsan and Bahçecioğlu (1970).

Fruits samples were labeled and harvested from mutant individuals. Fruit were then transferred to laboratory for pomological analysis. The fruit samples were weighed, and fruit diameter at the equator was measured with a digital calliper and also rind thickness was measured after cutting in half with a digital caliper (Mitutoyo CD-15CPX). The fruits were juiced using a standard juicer; then juice was weighed, and expressed as a percentage of the total fruit weight. Total soluble solids content (TSS) was determined with a portable refractometer (FG-103/113) using a few drops of juice. The total acidity (TA) of the juice was 
determined by titrating with $0.1 \mathrm{~N}$ sodium hydroxide $(\mathrm{NaOH})$ using phenolphthalein as the indicator. Ripening index was calculated as TSS/TA ratio.

The pomological traits determined by qualitative observations were scored as follows: fruit exterior view, 1 : very bad, 2: bad, 3: medium, 4: beautiful, 5: very beautiful; fruit shape, 1: obloid, 2: obloid-round, 3: spheroid; fruit rind structure, 1 : very rough, 2 : rough, 3 : slightly rough, 4 : smooth; fruit rind colour, 1: green, 2: green-yellow, 3: light yellow, 4: yellow, 5: dark yellow, 6: light orange, 7: orange, 8: dark orange; fruit flesh colour, 1: white, 2: green, 3: yellow, 4: orange; fruit juice colour, 1: white, 2: green, 3: yellow, 4: orange; fruit flesh texture, 1: coarse, 2: thin, 3: moderate, adherence of albedo to pulp, 1: weak, 2: medium, 3: strong (Çimen, 2018).

\section{Statistical Analysis}

Descriptive statistics of data obtained from pomological analysis of $\mathrm{mV}_{3}$ Ortanique mutant population were presented as minimum value, maximum value, mean value, and standard error. In order to examine the difference and similarity of the mutant individuals a distribution analysis and cluster analyses were performed based on pomological traits of the individuals. Pomological dendrogram was computed using 'Euclidean similarity coefficient' (Bozokalfa and Eşiyok, 2010). Also the regressions between seed number and some variables related to seed were calculated. All statistical analyses were performed by using JMP v11.00 statistics software and SigmaPlot ${ }^{\circledR}$ version 12.00 (Systat Software, San Jose, CA, USA) was used for data presentation.

\section{Results and Discussion}

Among the $\mathrm{mV}_{3}$ population derived by mutation from Ortanique tangor variety, 68 of the plants bore more than 10 fruits. The pomological analyses were performed in these individuals and the descriptive statistics were presented in Table 1. Considering minimum and maximum values of the variables related to fruit size, variation was higher in fruit weight in comparison to fruit height and diameter among the mutant individuals. Variability of $21.5 \%$ was recorded for fruit weight in the mutant population indicating high probability of selection for this trait. The fruit weight of the population varied between 90.00 to $287.60 \mathrm{~g}$ and the mean fruit weight of the $\mathrm{mV}_{3}$ plants was $179.93 \pm 39.49 \mathrm{~g}$ (Table 1). A distribution analysis based on pomological analysis showed that the fruit weight of $19 \%$ of the population varied from $75 \mathrm{~g}$ to $100 \mathrm{~g}$ whereas fruit weight of $2 \%$ of the population was more than $250 \mathrm{~g}$. Besides fruit weight of the $52 \%$ of the plants were between $150 \mathrm{~g}$ and $200 \mathrm{~g}$ (Figure 1). Mean fruit weight of non-irradiated Ortanique tangor (control) was 194.73 g. Population distribution analysis showed that $29 \%$ of the investigated $\mathrm{mV}_{3}$ plants had higher fruit weight in comparison to control. Fruit diameter in the population ranged from 56.72 to $84.79 \mathrm{~mm}$, whereas mean fruit diameter was $72.79 \pm 5.83 \mathrm{~mm}$. The coefficient of variations (CV) for fruit height, and fruit diameter were $8.31 \%$, and $8.01 \%$, respectively. These low CV values indicated low probability of selection for those traits in the present study (Table 1). Fruit shape index in the population ranged from $0.99 \mathrm{~mm}$ to $1.36 \mathrm{~mm}$, whereas the mean value was $1.17 \pm 0.05 \mathrm{~mm}$. Fruit index of Ortanique tangor was calculated as 1.26 in the same year (Figure 1).

Mutation breeding in citrus has a positive effect on fruit size and weight as well as several fruit quality parameters such as ripening period, seedlessness and coloration in fruit flesh (Vardi and Spiegel-Roy, 1988). Montañola et al. (2015) reported that 14 individuals improved by a mutation breeding program carried out in Chile, were found to be promising in terms of fruit weight. Goldenberg et al. (2014) observed that average fruit weight of one of the eight lowseeded irradiated mandarin varieties was significantly higher than those of varieties from non-irradiated trees. In addition, Rattanpal et al. (2019) marked that fruit weight should be used as a selection trait in the mutation breeding studies in case the variability coefficient is high.

Table 1. Maximum, minimum, mean, standard error, observation and measurement data of the mutant population derived by irradiating Ortanique tangor

\begin{tabular}{|c|c|c|c|c|c|}
\hline Variable & Minimum & Maximum & Mean & SE (mean) & $\mathrm{CV}(\%)$ \\
\hline Fruit weight (g) & 90.00 & 287.60 & 179.93 & \pm 39.49 & 21.95 \\
\hline Fruit height (mm) & 48.45 & 72.80 & 62.41 & \pm 5.19 & 8.31 \\
\hline Fruit diameter (mm) & 56.72 & 84.79 & 72.79 & \pm 5.83 & 8.01 \\
\hline Fruit shape index & 0.99 & 1.36 & 1.17 & \pm 0.05 & 4.67 \\
\hline Rind thickness (mm) & 2.76 & 5.47 & 4.28 & \pm 0.55 & 12.87 \\
\hline Peel number & 8.00 & 12.00 & 10.67 & \pm 0.67 & 6.25 \\
\hline Seed number per fruit & 0.60 & 13.10 & 5.78 & \pm 2.85 & 49.20 \\
\hline Juice content (\%) & 42.59 & 58.89 & 51.29 & \pm 3.58 & 6.97 \\
\hline Total soluble solids (\%) & 8.70 & 12.00 & 10.12 & \pm 0.85 & 8.37 \\
\hline Total acidity (\%) & 1.09 & 1.62 & 1.37 & \pm 0.13 & 6.74 \\
\hline TSS/TA & 5.96 & 9.20 & 7.46 & \pm 0.72 & 9.64 \\
\hline Fruit exterior view & 2.00 & 4.00 & 3.00 & \pm 0.17 & 5.76 \\
\hline Fruit shape & 1.00 & 2.00 & 1.06 & \pm 0.24 & 2.39 \\
\hline Fruit rind structure & 2.00 & 3.00 & 2.22 & \pm 0.42 & 6.93 \\
\hline Fruit rind color & 6.00 & 7.00 & 6.66 & \pm 0.48 & 7.15 \\
\hline Fruit flesh color & 4.00 & 4.00 & 4.00 & \pm 0.00 & 0.00 \\
\hline Fruit juice color & 4.00 & 4.00 & 4.00 & \pm 0.00 & 0.00 \\
\hline Fruit flesh texture & 1.00 & 3.00 & 1.56 & \pm 0.89 & 6.93 \\
\hline Adherence of albedo to pulp & 3.00 & 3.00 & 3.00 & \pm 0.00 & 0.00 \\
\hline
\end{tabular}



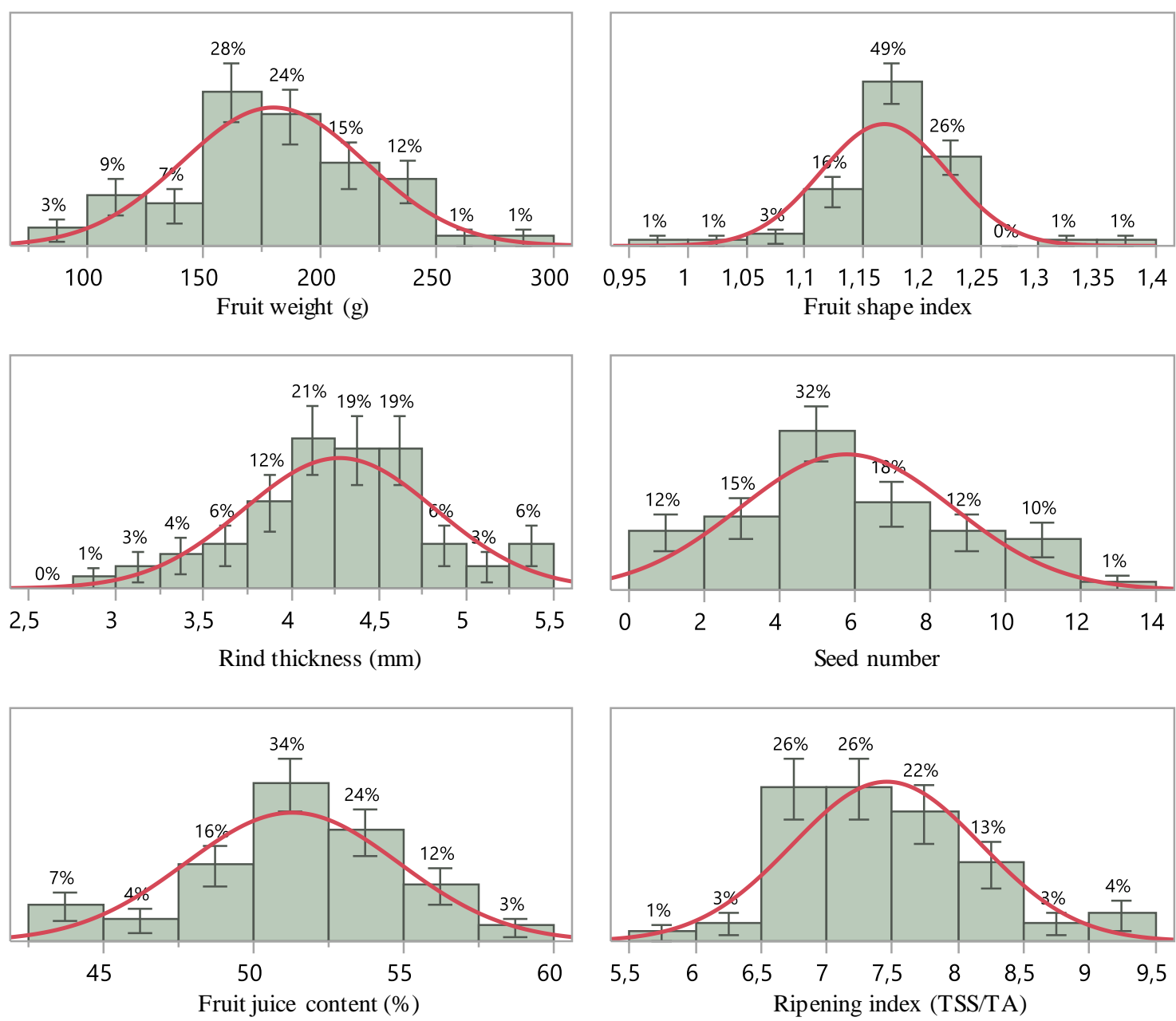

Figure 1. Distribution of fruit weight $(\mathrm{g})$, fruit index, rind thickness $(\mathrm{mm})$, number of seeds, maturity index (TSS/TA), juice content $(\%)$ in Ortanique $\mathrm{mV}_{3}$ mutant population

In citrus, fruit shape is also an important quality trait that attracts consumers' attention as well as fruit size. In general, mandarin varieties vary from flattened round to flat (Goldenberg et al., 2018). Goldenberg et al. (2014) reported that fruit shape index in mandarins showed difference because of the genetic variations that occur as a result of induced mutagenesis. In the present study, fruit shape index of the $99 \%$ of the mutant population was above 1 which indicates that fruits of mutant individuals had preserve the fruit shape standarts as a mandarin variety (Figure 1).

Rind thickness in the fruit samples ranged from 2.76 $\mathrm{mm}$ to $5.47 \mathrm{~mm}$, and the mean rind thickness was calculated as $4.28 \pm 0.55 \mathrm{~mm}$, as presented in Table 1 . Similar to population mean, the rind thickness was measured as $4.27 \mathrm{~mm}$ from fruit samples harvested from control. According to the results of the distribution analysis, the population variance was high in terms of rind thickness and $\mathrm{CV}$ was calculated as $12.87 \%$. Rind thickness of $40 \%$ of the population was between $4.00-4.50$ $\mathrm{mm}$, and $26 \%$ of the $\mathrm{mV}_{3}$ plants had lower rind thickness in comparison to control (Figure 1). In citrus mutation breeding, it was reported that rind thickness, fruit rind color, and texture were also affected and irradiation treatment had impact on fruit rind structure as well as many other fruit quality parameters (Donini, 1992). Goldenberg et al. (2014) reported that the rind thickness of irradiated
'Kedem', 'Michal', and 'Mor' mutants increased by the mutation treatment in comparison to control. In the present study, the population variance was low $(\mathrm{CV}=6.25 \%)$ in terms of peel number and peel number of the mutants investigated ranged between 8 to 12 whereas mean peel number of the population investigated was recorded as $10.67 \pm 0.67$ (Table 1).

Fruit samples of $68 \mathrm{mV}_{3}$ plants derived by irradiating Ortanique tangor were evaluated in terms of seed number under open pollination conditions. Number of seeds per fruit varied from 0.60 to 13.10 and the population mean was $5.78 \pm 2.85$ seed per fruit (Table 1). Seed number per fruit of non-irradiated Ortanique tangor was 10.7 under open pollination conditions. In this study, a significant amount of the individuals had lower seed number in comparison to Ortanique tangor variety. A distribution analysis showed that $27 \%$ of the population produced seed number lower than 4 seeds per fruit and those genotypes were considered commercially seedless. Especially fruits of 2-88, 5-70 and 6-25 coded mutant individuals were found to be promising in terms of seed number (Figure 2). It was reported that the average number of seeds per fruit of open-pollinated Ortanique tangor under CaliforniaRiverside conditions was 15.30 and similarly, the number of seeds per fruit ranged from 8 to 18 under Adana ecological conditions (Çimen, 2018). Seed number of 2-88, 5-70 and 6-25 coded mutant individuals was determined as 
$1.00,0.60$, and 1.80 , respectively among the mutant individuals evaluated by observing the first-year data. Similar to the present study, Froneman et al. (1996) subjected pomelo, mandarin, and orange varieties to gamma rays in order to obtain seedless clones and they developed 13 seedless and low-seeded genotypes. By irradiation of budwoods of Monreal clementine and W. Murcott mandarin, seedless 'Monreal Verde' and 'Tango' were improved, respectively (Nicotra, 2001; Roose and Williams, 2007). Williams (2012) stated that irradiation had been used principally to reduce the seed content of normally seedy varieties and has been a more rapid method of achieving these goals than does hybridization. Author also indicated that several seedless and low-seeded mandarin selections including 'Tango', 'DaisySL', 'KinnowLS', and 'FairchildLS' had been developed by mutation breeding. On the other hand, a breeding program in Italy focused on developing pigmented and seedless

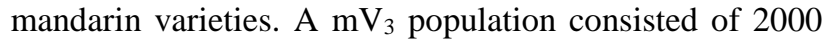
plants developed by irradiating budwoods of Tarocco Meli, Moro M45 and Sanguinello 49-5-5 blood oranges with gamma rays at a dose of 40 Gy by CREA (Caruso et al., 2016).

In the $\mathrm{mV}_{3}$ population investigated in the present study, fruit juice content of the mutant individuals ranged from 42.59 to $58.89 \%$, and population $\mathrm{CV}$ was low $(6.97 \%)$ in terms of fruit juice concentration. Fruit juice concentration of the non-irradiated Ortanique tangor fruits was $49.86 \%$ and the mutant population mean was $51.29 \%$ (Table 1). A distribution analysis showed that $27 \%$ of the $\mathrm{mV} 3$ plants had lower fruit juice concentration than Ortanique (Figure 1).
Total soluble solids (TSS) of the mutant individuals range between $8.70 \%$ and $12.00 \%$ whereas mean TSS was calculated as $10.12 \%$. Besides, total acidity (TA) of the $\mathrm{mV}_{3}$ Ortanique population was $1.37 \%$ and this variable had a low CV value $(6.74 \%)$. TSS/TA ratio is an important variable in citriculture for determining ripening and harvest time. TSS/TA ratio of the $\mathrm{mV}_{3}$ Ortanique mutant population varied from 5.96 to 9.20 and the population mean was 7.46. TSS/TA ratio of the non-irradiated Ortanique tangor was calculated as 8.39 in the same harvest date and the coefficient variations of population was 9.64 (Table 1). A large amount of the population (78\%) had lower TSS/TA ratio than Ortanique tangor according to a distribution analysis (Figure 1).

In terms of the pomological traits determined by qualitative observations, the average fruit exterior view of samples was found to be medium (3.00 points) and the fruit shape was flattened with an average of 1.06 points. The average fruit rind structure of the $\mathrm{mV}_{3}$ population investigated in this study was rough ( 2.22 points) and the mean fruit rind colour was orange with 6.66 points. Fruit flesh and juice colour of the $\mathrm{mV}_{3}$ mutant individuals were orange with 4.00 points. Fruit flesh texture scores ranged from 1 to 3 , with a mean flesh texture of 1.56 points. The scores related to the adherence of albedo to pulp of all the mutant individuals were found to be strong with 3 points score. The low CV values of pomological traits, determined by qualitative observations, indicated low probabilities of selection for those traits in the present study (Table 1).
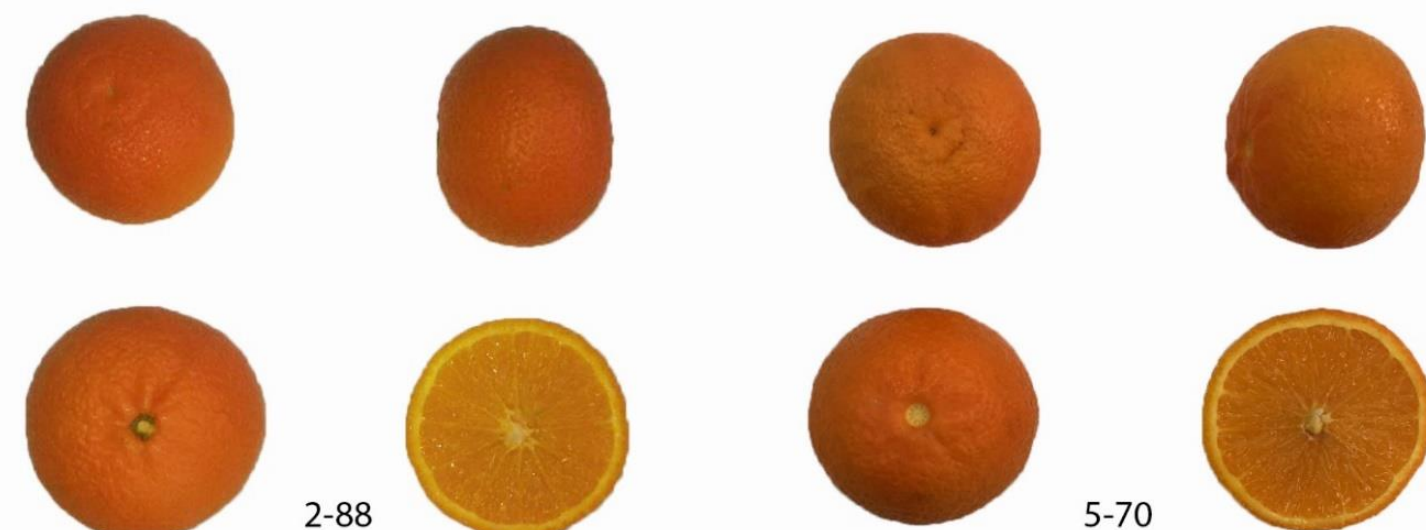

\section{2-88}
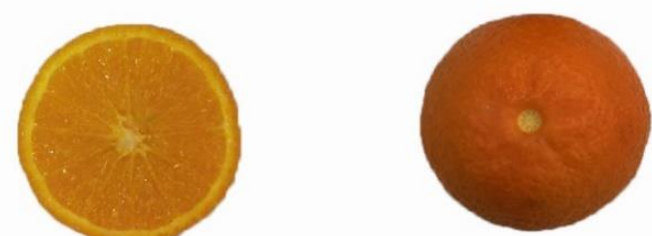

5-70
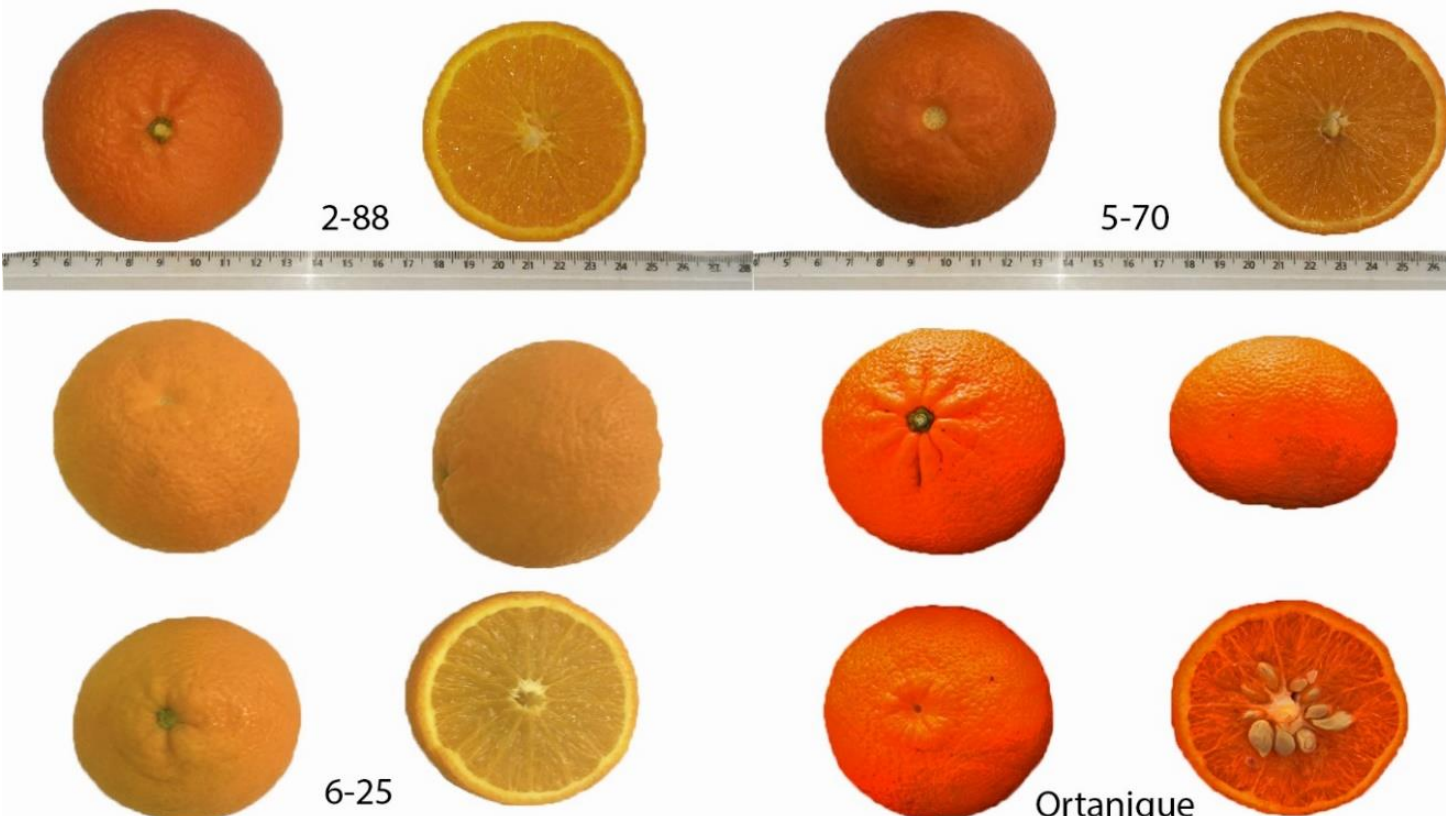

6-25
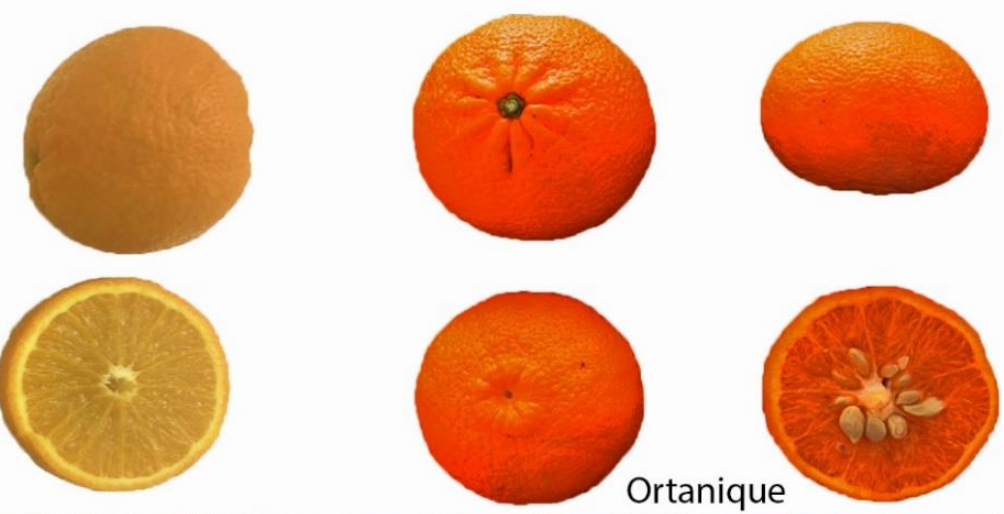

Figure 2. Fruit photographs of 2-88, 5-70, 6-25 coded $\mathrm{mV}_{3}$ Ortanique mutants and non-irradiated Ortanique tangor fruits 
Figure 3 showed the relationship of seed number with fruit weight, fruit juice content, ripening index (TSS/TA), and rind thickness $(\mathrm{mm})$ of the investigated $\mathrm{mV}_{3}$ mutant individuals. Considering the relationship between fruit weight and seed number, very low significant relationship was observed in the mutant population (Figure 3A). Although number of seeds of the mutants 2-88 and 6-25 were lower than the Ortanique tangor, fruit weights were observed to be higher. On the other hand, 5-70 had lower fruit weight than Ortanique. Fruit juice of $2-88$ was very low in comparison to Ortanique whereas 5-70 and 6-25 genotypes had similar or higher fruit juice content (Figure 3B). TSS/TA ratios of all the promising mutant individuals were lower than Ortanique which indicated that all low-seeded mutants were early ripening than Ortanique (Figure 3C). Rind thickness of genotype 5-70 were similar to Ortanique variety, however mutants 2-88 and 6-25 had thicker fruit rind than Ortanique (Figure 3D).

In 'Hierarchical Cluster' analysis, genotypes are clustered or grouped according to their similarities and dendrograms are formed regarding the similarity index (Bozokalfa and Eşiyok, 2010). In this study, the dendrogram, belonging to the pomological traits of 68 mutant individuals evaluated in terms of fruit quality, was formed using 'Euclid' similarity coefficient and the similarity index ranged between $34.48 \%$ and $93.10 \%$ (Figure 4).

Mutant individuals evaluated in terms of pomological traits were divided into two main groups. The 3-60, 3-57,
2-82, and 2-17 coded Ortanique mutants were grouped separately from the other individuals in the mutant population due to the variables of fruit rind structure and colour. In the first subgroup, the 2-17 coded mutant was distinguished from other individuals in the population with a similarity index of $36.59 \%$. In the second subgroup 5-70 was separated from others due to the variables related to fruit size such as fruit weight and diameter with a similarity index of $38.82 \%$ (Figure 4). Koehler-Santos et al. (2003) reported that the genetic distance between mandarins was 0.32 (0.68 similarity level) in their molecular characterization study with 34 mandarins. Similarly, in this study, mutant individuals developed from Ortanique tangor were compared based on their pomological traits and the lowest similarity was found to be $34.48 \%$.

\section{Conclusion}

In the present study, we investigated the effects of mutagenesis on seed number and some fruit quality traits of Ortanique tangor variety depending on the primarily data and observations of first year's fruit crop. Budwoods of Ortanique tangor were subjected to a mutation-inducing process, which led to the production of seedless mutants of the variety. Of the 852 Ortanique $\mathrm{mV}_{3}$ individuals planted in the experimental orchard, 68 individuals bore more than 10 fruits in the first year and 19 pomological variables were investigated in those genotypes.
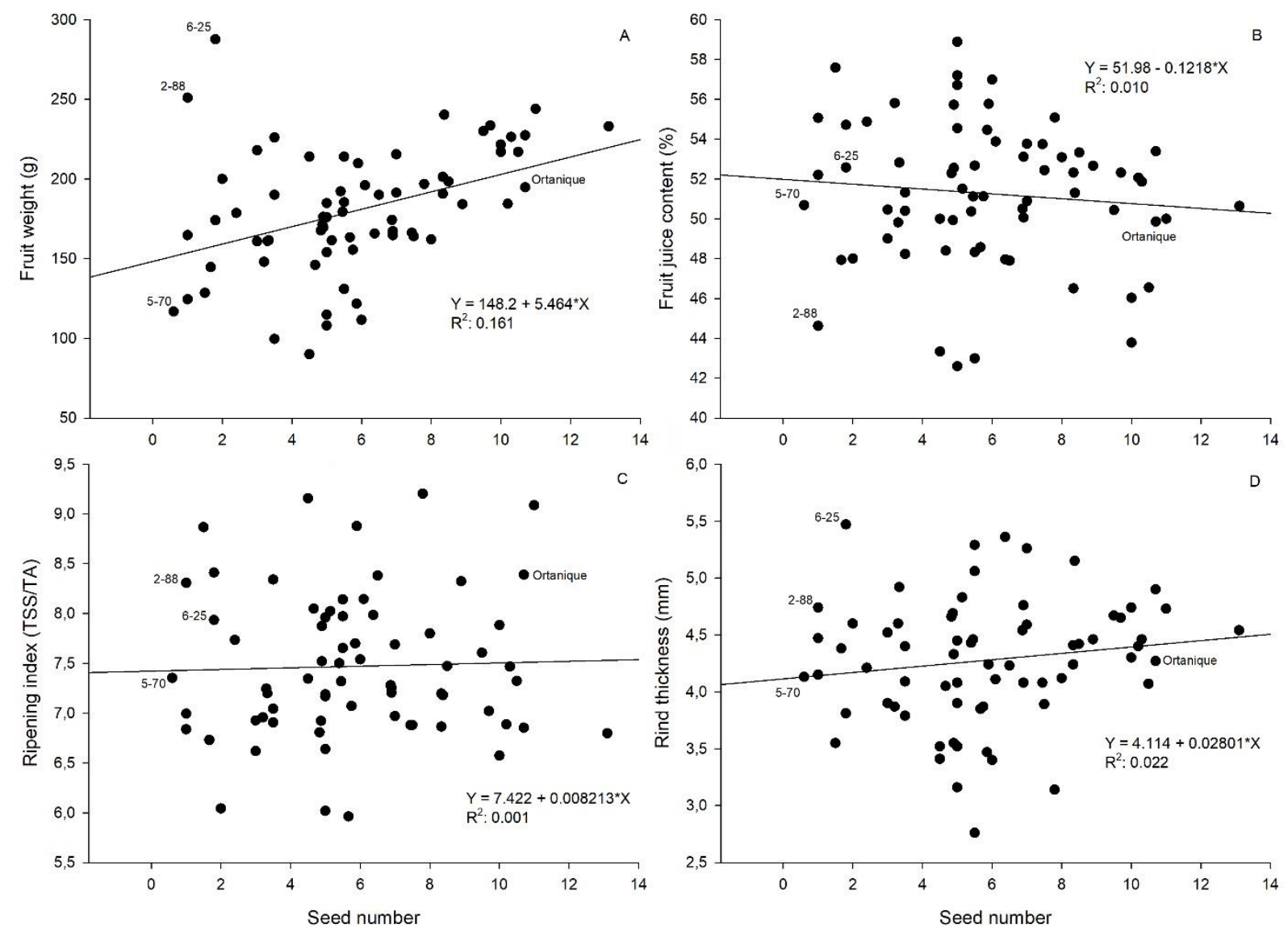

Figure 3. Relationship of seed number vs fruit weight, fruit juice content (\%), ripening index (TSS/TA), and rind thickness $(\mathrm{mm})$ of Ortanique $\mathrm{mV}_{3}$ mutant population 


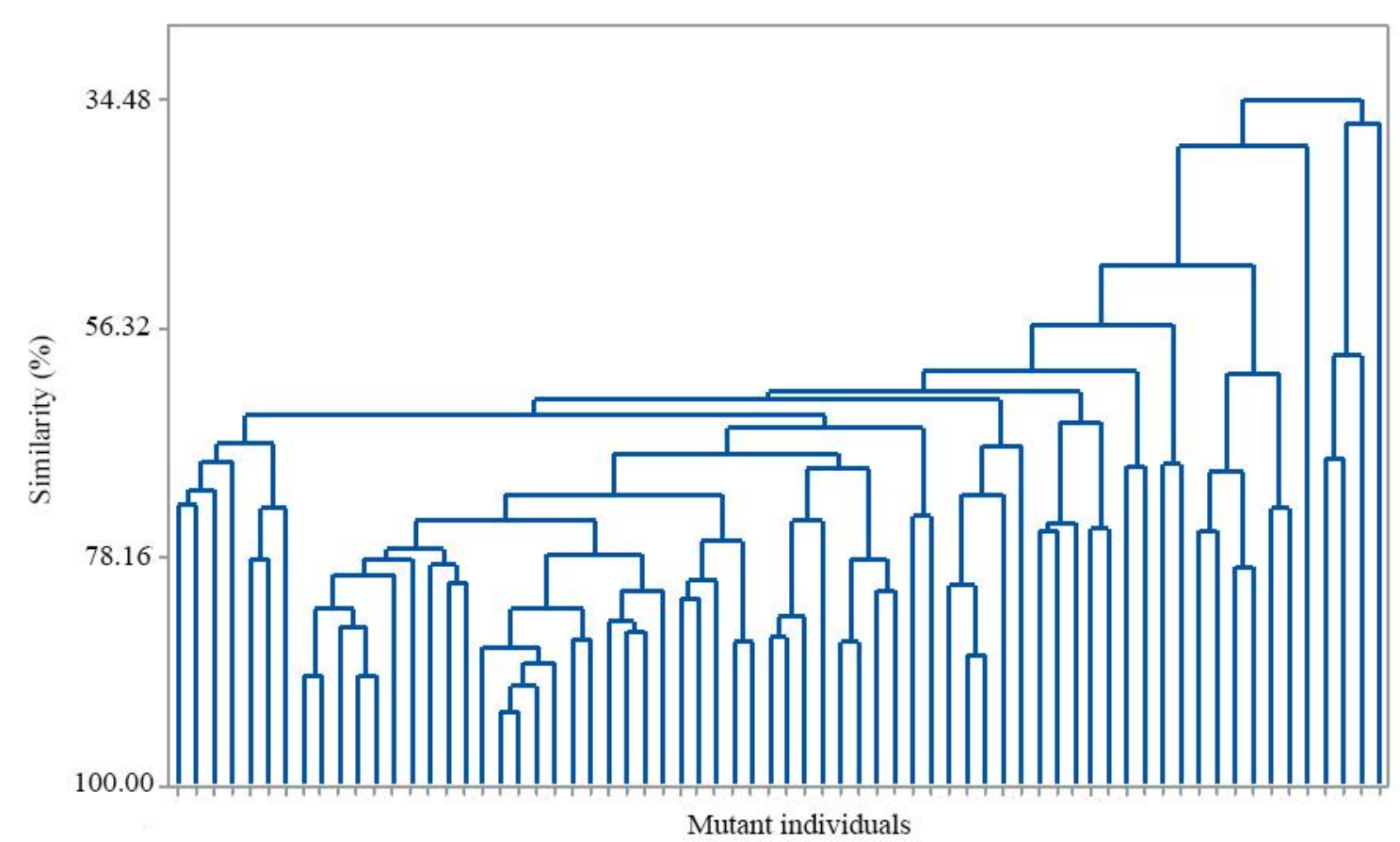

Figure 4. Similarity dendrogram between groups of Ortanique tangor mutant population based on pomological traits

In the present study, we observed that $27 \%$ of the plants under open-pollination conditions had a seed number between 0-4. In addition, we showed that the fruit quality traits of approximately $40 \%$ of the population were similar to the Ortanique tangor variety in terms of size, fruit height and fruit diameter. In addition, fruit yield of the mutant genotypes will be evaluated for consecutive years. The promising mutant individuals are now under investigation in the field to confirm their stability, agronomic advantages and for genetic tests with molecular markers.

\section{Acknowledgements}

This research was supported by the grant from the Çukurova University, Scientific Research Projects Coordination Unit (FDK-2015-3290) and reproduced from a part of the $\mathrm{PhD}$ thesis of the corresponding author.

\section{References}

Bozokalfa MK, Eşiyok D. 2010. Biber (Capsicum annuum L.) Aksesyonlarında Genetik Çeşitliliğin Agronomik Özellikler ile Belirlenmesi. Ege Üniversitesi Ziraat Fakültesi Dergisi, 47:123-134.

Caruso M, Russo R, Romano F, Cirrone G, Gattolin S, Rossini L, Cuttone G, Russo G. 2016. Citrus Breeding Activities at Crea, Italy. International Citrus Congress 2016, Brazil, 18-23 September 2016, Abstract Book, 1:101.

Çimen B. 2018. Klasik ve Biyoteknolojik Islah Yöntemleriyle Yeni Turunçgil Çeşit ve Anaçlarının Geliştirilmesi. Doktora Tezi, Çukurova Üniversitesi Fen Bilimleri Enstitüsü.

Demirkeser TH, Kaplankıran M, Toplu C, Y1ldız E. 2009. Yield and fruit quality performance of Nova and Robinson mandarins on three rootstocks in Eastern Mediterranean. Afr. J. Agric. Res., 4:262-268.

Donini B. 1992. FAO/IAEA International training course on the induction and use of mutations in plant breeding. Seibersdorf:1-10.
FAO. 2019. FAOSTAT [Internet]. [cited 2019 Apr 8]. Available from: http://www.fao.org/faostat/en/\#data/QC

Froneman I, Breedt J, Koekemoer H, Van Rensburg P. 1996. Producing Seedless Citrus Cultivars with Gama Irradiation. International Citrus Congress 1996, Sun City, South Africa, 12-17 May 1996, 1:159-163.

Goldenberg L, Yaniv Y, Porat R, Carmi N. 2014. Effects of Gamma-Irradiation Mutagenesis for Induction of Seedlessness, on the Quality of Mandarin Fruit. Food and Nutrition Sciences, 05:943-952.

Goldenberg L, Yaniv Y, Porat R, Carmi N. 2018. Mandarin fruit quality: a review. J. Sci. Food Agr., 98:18-26.

Handaji N, Arsalene N, Aderdour T, Essalhi M, Labek K, Yacoubi R, Benyahia H. 2016. Effect Of Gama Ray Irradiation On Fruit Quality Variability of Marisol Clementine. International Citrus Congress 2016, Brazil, 1823 September 2016, 1:102.

Hensz RA. 1971. 'Star Ruby', a new deep-red fleshed grapefruit variety with distinct tree characteristics. Journal of the Rio Grande Valley Horticulture Society, 25:54-58.

Koehler-Santos P, Dornelles ALC, Freitas LB de. 2003. Characterization of mandarin citrus germplasm from Southern Brazil by morphological and molecular analyses. Pesqui. Agropecu. Bras, 38:797-806.

Montañola M, Galaz A, Gambardella M, Mártiz J. 2015. New Low Seeded Mandarin (Citrus reticulate) and Lemon $(C$. limon) Selections Obtained by Gamma Irradiation. Acta Hortic., 1065:543-548.

Nicotra A. 2001. Mandarin-like hybrids of recent interest for fresh consumption. Problems and ways of control [Internet]. [cited 2019 Oct 1]. Available from: http://agris.fao.org/agrissearch/search.do?recordID=XF2004414601

Ollitrault P, Dambier D, Luro F, Froelicher Y. 2008. Ploidy Manipulation for Breeding Seedless Triploid Citrus. In: Janick J, editor. Plant Breeding Reviews [Internet]. Hoboken, NJ, USA: John Wiley \& Sons, Inc.; [cited 2019 Mar 7]; p. 323-352. Available from: http://doi.wiley.com/10.1002 /9780470380130.ch7 
Ollitrault P, Terol J, Chen C, Federici CT, Lotfy S, Hippolyte I, Ollitrault F, Bérard A, Chauveau A, Cuenca J, Costantino G, Kacar Y, Mu L, Garcia-Lor A, Froelicher Y, Aleza P, Boland A, Billot C, Navarro L, Luro F, Roose ML, Gmitter FG, Talon M, Brunel D. 2012. A reference genetic map of C. clementina hort. ex Tan.; citrus evolution inferences from comparative mapping. BMC Genomics, 13:593. doi: 10.1186/1471-216413-593

Özsan M, Bahçecioğlu H. 1970. Akdeniz Bölgesinde Yetiştirilen Turunçgil Tür ve Çeşitlerinin Değişik Ekolojik Şartlar Altında Gösterdikleri Özellikler Üzerinde Araştırmalar. Ankara: TÜBİTAK Matbaası.

Rattanpal HS, Singh G, Gupta M. 2019. Studies on mutation breeding in mandarin variety Kinnow. Current Science, 116(3):483-487.

Roose ML, Williams TE. 2007. A new seedless mid-late season irradiated selection of W. Murcott (Afourer) mandarin developed by the University of California Citrus Breeding Program. Google Patents:2.

Saunt J. 2000. Citrus Varieties of The World. England: Sinclair International.
Shahid AK, Abdus S, Roshan Z. 2011. Development of sparseseeded mutant kinnow (Citrus reticulata Blanco) through budwood irradiation. Afr. J. Biotechnol., 10:14562-14565.

Vardi A, Spiegel-Roy P. 1988. A new approach to selection for seedlessness. International Citrus Congress 1988, Tel Aviv, Israel, 6-11 March 1988, 131-134.

Williams T. 2012. Experiences in the development, release and commercialization of new irradiated citrus varieties from the citrus breeding program at the University of California Riverside. Proc. International Citrus Congress 2012, Valencia, Spain, 18-23 November 2012, 38.

Williams T, Roose ML. 2008a. Tango-A New, Very LowSeeded, Late Season Irradiated Selection of W. Murcott Mandarin from the University of California Riverside. International Citrus Congress 2008, Wuhan, China 26-30 October 2008, 1:202.

Williams T, Roose ML. 2008b. Daisy SL, Fairchild SL and Kinnow SL-Three New, Very Low-Seeded, Mid Season Irradiated Selection of W. Murcott Mandarin from the University of California Riverside. International Citrus Congress 2008, Wuhan, China 26-30 October 2008, 1:203. 